Kansas State University Libraries

New Prairie Press

\title{
OPTIMUM DESIGN FOR EXPONENTIAL MODEL USING AN EXPONENTIAL LOSS FUNCTION AND ITS APPLICATIONS IN AGRICULTURE
}

Imad H. Khamis

Follow this and additional works at: https://newprairiepress.org/agstatconference

Part of the Agriculture Commons, and the Applied Statistics Commons

\section{(c) (1) $\Theta(9$}

This work is licensed under a Creative Commons Attribution-Noncommercial-No Derivative Works 4.0 License.

\section{Recommended Citation}

Khamis, Imad H. (2000). "OPTIMUM DESIGN FOR EXPONENTIAL MODEL USING AN EXPONENTIAL LOSS FUNCTION AND ITS APPLICATIONS IN AGRICULTURE," Conference on Applied Statistics in Agriculture. https://doi.org/10.4148/2475-7772.1251

This is brought to you for free and open access by the Conferences at New Prairie Press. It has been accepted for inclusion in Conference on Applied Statistics in Agriculture by an authorized administrator of New Prairie Press. For more information, please contact cads@k-state.edu. 


\title{
OPTIMUM DESIGN FOR EXPONENTIAL MODEL USING AN EXPONENTIAL LOSS FUNCTION AND ITS APPLICATIONS IN AGRICULTURE
}

\author{
Imad H. Khamis \\ DEPARTMENT OF PSYCHIATRY AND BEHAVIORAL SCIENCES \\ SCHOOL OF MEDICINE \\ MIAMI , FL
}

Key Words - Accelerated life test, constant-stress, maximum likelihood

\begin{abstract}
Accelerated life testing has been used for years in engineering. Test units are run at high stress and fail sooner than at design stress. The lifetime at design stress is estimated by extrapolation using a regression model. This paper considers the optimum design of accelerated life tests in which two levels of stresses, high and low are constantly applied. For the exponential model the expected value of an exponential loss function of the parameter is to be used. The initial sample proportion allocated to the high stress which minimizes the expected loss function is determined. In the agriculture context, plants or animal may be the items placed on test and dosage of a chemicals, amount of fertilizer, may be the stress variable. In this paper I suggest several potential applications of constant testing in agriculture and present inferential procedure in the case in which observations have the exponential distribution.
\end{abstract}

\section{INTRODUCTION}

This paper introduces constant-stress testing to the agricultural research community. The paper begins by reviewing the engineering origins of constant-stress testing. See Nelson (1990) and Khamis (1997). Accelerated life testing (ALT) quickly yields information on product life. Test units are run at high stress and fail sooner than at design stress. The lifetime at design stress is estimated by extrapolation using a regression model. In constant-stress testing, a test unit is run at a fixed stress until either failure occurs or the test is terminated. For instance, in replacing 30 lightbulbs at each of three voltages $(130,140,150)$, a constant stress design might place 10 lightbulbs at each of three voltageas an optimum criterion to estimate the distribution of the lifetime of the lightbulb. For the exponential model the expected value of an exponential loss function of the parameter is to be minimized to obtain the optimum design. See (Higgins and Tsokos, 1980). In the agriculture context, plants or animal may be the items placed on test and dosage of a chemicals, amount of fertilizer, may be the stress variable. In this paper I suggests several potential applications of constant testing in agriculture and presents an inferential procedure in the case in which observations have the exponential distribution. 


\section{EXAMPLES IN AGRICULTURE}

Optimum design for constant-stress testing has not been wildly used in agriculture. Such testing is potentially useful when a stress variable is applied to a plant, or other experimental unit. The following examples are included to demonstrate the applications.

Example 1. A researcher may be interested in modeling the effect of a potentially lethal drug on some physical characteristic of a laboratory animal. Here the stress variable would be drug level and the response would be the time it takes to reach some critical life stage (e.g. time to reach a critically low white blood count or time to death). In constant-stress testing, with 30 animals, 10 animals may be assigned to low stress and the remaining 20 to the high stress. When an animal reaches the desired critical life stage or death after having been administrated just a single level of the drug, the animal will be considered a failure.

Example 2. Similar to example one, a researcher may be interested in the time it takes a plant to reach a critical life stage or death after it has been deprived of an essential nutrient. The typical constant-stress experiment would place each plant under just one level of the nutrient. Some of the plants would subjected to a low nutrient level, and the remaining plants will receive the high level of the nutrient. The plant are observed until a critical life stage or death occurs.

Example 3. A veterinarian may be interested in determining the effects of exercise on the time it takes an animal to reach a certain physiological state. In constant-stress testing, each animal would be placed at single exercise level during a given run of experiment, and the time it takes to reach the desire state, if at all, would be recorded.

\section{THE MODEL}

In this section the optimum constant-stress test is derived for the exponential distribution. Although optimum constant-stress design has been investigated extensively, this result appears to give different than those previously published.

\section{Basic Assumptions}

The notation used in the following discussion are described as:

(1) Testing is done at stress levels $x_{1}$ and $x_{2}$ where $x_{1}<x_{2}$.

(2) The distribution of the test unit is exponential. That is

$$
\begin{aligned}
& \left.f_{1}(t)=\mid \begin{array}{ll}
\theta_{1} & \exp \left(-\theta_{1} t\right)
\end{array}\right], \quad\left(\text { stress } x_{1}\right) \\
& \left.f 2(t)=\theta_{2} \exp \left(-\theta_{2} t\right), t \geq 0, \quad \text { (stress } \mathrm{x}_{2}\right) .
\end{aligned}
$$


where $\theta_{i}$ at stress $x_{i}$ is assumed to be described by

$$
\log \left(\theta_{i}\right)=\beta_{o}+\beta_{1} x_{i}
$$

(3) The lifetimes of test units are independent and identically distributed.

(4) All $n$ units are placed on test, $n_{1}$ units assigned to the low stress $x_{1}$, and the remaining units $\mathrm{n}_{2}=\mathrm{n}-\mathrm{n}_{1}$ are assigned to the high stress $\mathrm{x}_{2}$. The test continue until all units fail.

\section{THE ESTIMATION METHOD}

The likelihood function from observations $\mathrm{T}_{\mathrm{ij}}=\mathrm{t}_{\mathrm{ij}}, \mathrm{i}=1,2, \mathrm{j}=1,2 \ldots, \mathrm{n}_{\mathrm{i}}$ is:

$L\left(\theta_{1}, \theta_{2}\right)=\prod_{j=1}^{n_{1}}\left[\theta_{1} \exp \left(-\theta_{1} t_{1 j}\right)\right] \prod_{j=1}^{n_{2}}\left[\theta_{2} \exp \left(-\theta_{2} t_{2 j}\right)\right]$

where $n=n_{1}+n_{2}$. Substituting (1) for $\theta_{i}, i=1,2$, in (2), we find the log likelihood function as a function of unknown parameters $\beta_{\mathrm{o}}$ and $\beta_{1}$. That is,

$$
\begin{aligned}
\log L\left(\beta_{o}, \beta_{1}\right) & =n \beta_{o}+\left(n_{1} x_{1}+n_{2} x_{2}\right) \beta_{1}-U_{1} \exp \left(\beta_{o}+\beta_{1} x_{1}\right) \\
& -U_{2} \exp \left(\beta_{o}+\beta_{1} x_{2}\right)
\end{aligned}
$$

where

$$
U_{1} \equiv \sum_{j=1}^{n_{1}} t_{1 j} \text { and } U_{2} \equiv \sum_{j=1}^{n_{2}} t_{2 j}
$$

MLEs for the model parameters $\beta_{\mathrm{o}}$ and $\beta_{1}$ can be obtained explicitly by solving the following two equations

$$
\begin{gathered}
\frac{\partial \log L\left(\beta_{o}, \beta_{1}\right)}{\partial \beta_{o}}=-\left(n_{1}+n_{2}\right)+U_{1} \exp \left(-\beta_{o}-\beta_{1} x_{1}\right)+U_{2} \exp \left(-\beta_{o}-\beta_{1} x_{2}\right) \\
=0 \\
\frac{\partial \log L\left(\beta_{o}, \beta_{1}\right)}{\partial \beta_{1}}=-\left(n_{1} x_{1}+n_{2} x_{2}\right)+U_{1} \exp \left(-\beta_{o}-\beta_{1} x_{1}\right) x_{1}+U_{2} \exp \left(-\beta_{o}-\beta_{1} x_{2}\right) x_{2} \\
=0 .
\end{gathered}
$$


That is,

$$
\begin{aligned}
& \hat{\beta}_{0}=\frac{x_{2} \ln \frac{n_{1}}{U_{1}}-x_{1} \ln \frac{n_{2}}{U_{2}}}{x_{2}-x_{1}} \\
& \hat{\beta}_{1}=\frac{\ln \left(\frac{n_{2} U_{1}}{n_{1} U_{2}}\right)}{x_{2}-x_{1}}
\end{aligned}
$$

Lemma: Suppose $T_{i j}$ is distributed exponentially with scale parameter $\theta_{i}, i=1,2, j=1,2, \ldots, n_{i}$. Then the random variables

$$
2 n_{i} e^{\beta_{0}+\beta_{1} x_{i}} m_{i} \quad \text { and } 2 n_{i} e^{\beta_{0}+\beta_{1} x_{i}}\left(t_{i}-n_{i} m_{i}\right)
$$

where

$$
m_{i}=\min \left\{t_{i j} j=1,2, \ldots, n_{i}\right\}
$$

are independent and distributed chi-square with 2 and $\left(2 n_{i}-2\right)$ degrees of freedom respectively. See Lawless (1982).

From the above lemma we have

$$
2 n_{i} e^{\beta_{0}+\beta_{1} x_{i}} t_{i}
$$

is distributed chi-square distribution with $2 \mathrm{n}_{\mathrm{i}}$ degrees of freedom and the ratio

$$
\frac{\left(2 e^{\beta_{0}+\beta_{1} x_{1}} t_{1}\right) / 2 n_{1}}{\left(2 e^{\beta_{0}+\beta_{1} x_{2}} t_{2}\right) / 2 n_{2}}=\frac{U_{1} n_{2}}{U_{2} n_{1}} e^{\beta_{1}\left(x_{1}-x_{2}\right)}
$$

is distributed $\mathrm{F}$ with $2 \mathrm{n}_{1}$ and $2 \mathrm{n}_{2}$ degrees of freedom. Using the expression in (3), (4) also becomes

$$
\frac{U_{1} n_{2}}{U_{2} n_{1}}=e^{\hat{\beta}_{1}\left(x_{2}-x_{1}\right)}
$$

Substitute (5) in (4) to get 


$$
e^{\left(\hat{\beta}_{1}-\beta_{1}\right)\left(x_{2}-x_{1}\right)}
$$

which distributed $\mathrm{F}$ with $2 \mathrm{n}_{1}$, and $2 \mathrm{n}_{2}$, degrees of freedom.

An exponential loss function of the parameter $\beta_{1}$ for given values of $x_{1}$ and $x_{2}$ can be written as

$$
L\left(\hat{\beta}_{1}, \beta_{1}\right)=\left(e^{\left(\hat{\beta}_{1}-\beta_{1}\right)\left(x_{2}-x_{1}\right)}-1\right)^{2}
$$

Note that the loss function of $\beta_{1}$ is used because the rate of change of the log mean lifetime over stress levels is important in applications. In order to find the expected value of the loss function (6), it is important to note that the F distribution doesn't have a second moment when the second degrees of freedom is less than or equal to 4 . Therefore designs are restricted to the case where $3 \leq n_{2} \leq n-1$. Also, we note $n_{2}$ has a binomial distribution with $n$ and $\pi_{2}$ parameters. That is

$$
P\left(n_{2}=s \mid 3 \leq n_{2} \leq n-1\right)=\frac{C_{k}^{n} \pi_{2}^{s}\left(1-\pi_{2}\right)^{n-s}}{\sum_{s=3}^{n-1} C_{k}^{n} \pi_{2}^{s}\left(1-\pi_{2}\right)^{n-s}}
$$

Thus, the expected value of the loss function for the parameter $\beta_{1}$ is

$$
\begin{gathered}
E\left(\left(e^{\left(\hat{\beta}_{1}-\beta_{1}\right)\left(x_{2}-x_{1}\right)}-1\right)^{2} \mid 3 \leq n_{2} \leq n-1\right)= \\
\sum_{k=3}^{n-1}\left[\left(\frac{k}{k-1}\right)^{2} \frac{n-1}{(n-k)(k-2)}+\left(\frac{1}{k-1}\right)^{2}\right]_{k}^{n} \pi_{2}^{k}\left(1-\pi_{2}\right)^{n-k} \\
\sum_{k=3}^{n-1} C_{k}^{n} \pi_{2}^{k}\left(1-\pi_{2}\right)^{n-k}
\end{gathered}
$$

Note that this expression is independent of any stress level.

\section{OPTIMUM TESTS DESIGN}

A design is defined to be optimum if it minimize the expected value of the loss function. The design which minimizes (7) depends on the proportion $\pi_{2}$ of the test units allocated to the stress $\mathrm{x}_{2}$ with the restriction $0<\pi_{2}<1$. The optimum design for $\pi_{2}^{*}$ which minimizes (7) can be found numerically. Khamis (1997) obtained for given values of $x 1=0.2$ and $\times 2=1.0$ the optimum $\pi_{2}^{*}=0.25$ which also minimize the asymptotic variance of MLE of the log mean lifetime at the design stress for large $n$. This result is asymptotic. However, the optimum design here is exact and depends on the sample size. Table 1 shows the optimum $\pi^{*}{ }_{2}$ that minimizes (7) for different sample sizes $(n=10,15,20,25,30,35,40,50)$. Table 1 also shows the relative 
efficiency of the optimum design obtained by Khamis (1997). The relative efficiency, denoted Reff, is defined by

$$
\operatorname{Reff}=\frac{\min _{\pi_{2}} E\left(\left(e^{\left(\hat{\beta}_{1}-\beta_{1}\right)\left(x_{2}-x_{1}\right)}-1\right)^{2} \mid 3 \leq n_{2} \leq n-1\right)}{\min _{\pi_{2}=0.25} E\left(\left(e^{\left(\hat{\beta}_{1}-\beta_{1}\right)\left(x_{2}-x_{1}\right)}-1\right)^{2} \mid 3 \leq n_{2} \leq n-1\right)}
$$

For example when the sample size is 15 the proportion of experimental units that fail at high stress $\mathrm{x}_{2}$ under the optimal design is .62, and this design is $34 \%$ more efficient than the optimum design obtained by maximum likelihood method.

Table1: Comparing the efficiencies of the approximate and exact methods

$\begin{array}{llllllllll}\mathrm{n} & 10 & 15 & 20 & 25 & 30 & 35 & 40 & 50 & 80 \\ \hat{\pi}_{2} & 0.68 & 0.62 & 0.59 & 0.58 & 0.57 & 0.56 & 0.55 & 0.54 & 0.53 \\ \text { Reff } & 0.46 & 0.34 & 0.32 & 0.34 & 0.38 & 0.43 & 0.48 & 0.55 & 0.63\end{array}$

\section{References}

Higgins, J.J. and C.P. Tsokos (1980). Study of the loss function on Bayes Estimates of Failure Intensity MTBF, and Reliability. Applied Mathematics and Computation. Vol 6 , 145-166.

Khamis, I. H. (1997). Comparison between constant and step-stress tests for Weibull models. International Journal of Quality and Reliability Management, Vol 14, Mo. 1, 7481 .

Lawless, J. F. (1982). Statistical Models and Methods for Lifetime Data. Wiley. New York.

Nelson, W. (1990). Accelerated Testing Statistical Models, Test Plans, and Data Analysis. Wiley, New York. 